\title{
Identifying dead regions in the cochlea through the TEN Test
}

\section{Regina TS Jacob ${ }^{1}$, João Cândido Fernandes ${ }^{2}$, Jair Manfrinato $^{3}$, Maria Cecília M Iório ${ }^{4}$}

Keywords: Hearing Loss. Hearing Aids. Cochlea. Dead Cochlear Regions

\section{Summary}

\begin{abstract}
A regions. Aim: To investigate cochlear dead regions in sensorineural hearing loss subjects using the TEN test. Site: CEDALVI/ HRAC-USP-Bauru/Sao Paulo/Brazil, August 2003 to February 2004. Study Design: A contemporary crosssectional cohort study. Material and Methods: The TEN test was applied in three groups: G1(5 women with pure-tone thresholds within normal limits); G2(4 women and 5 men with moderate sensorineural flat hearing loss); G3(19 women and 24 men with mild to severe sloping sensorineural hearing loss). Results: In the G1 group the TEN value required to eliminate the test tone was, on average, close to the absolute threshold for all frequencies. No dead regions were found in the ears tested in group G2. 76 ears were tested in group G3, and six showed no evidence of dead regions in the cochlea. Conclusions:The TEN test was an effective test to indicate a dead region in the cochlea of subjects with sloping sensorineural hearing loss. There is evidence that puretone detection is different for subjects with high frequency sensorineural hearing loss and flat hearing loss; we observed a significant difference between the masked threshold and the absolute threshold only in sloping hearing loss and not for flat hearing loss.
\end{abstract}

\footnotetext{
${ }^{1}$ Doctor on Rehabilitation Science/Human Communication Disorders at the Sao Paulo University Craniofacial Anomalies Rehabilitation Hospital/Bauru Campus (HRAC/ USP/Bauru), Speech Therapist of the CEDALVI/HRAC/USP Bauru.

${ }^{2}$ Lecturer at UNESP/Bauru, Professor of the post-graduate program on Rehabilitation Science/Human Communication Disorders at HRAC/USP/Bauru.

${ }^{3}$ Doctor on Agricultural Science at UNESP/Botucatu, Head of the Production Engineering Department at UNESP/ Bauru.

${ }^{4}$ Doctor on Human Communication Disorders at the UNIFESP/EPM, Adjunct Professor of the Speech Therapy Course at UNIFESP/EPM. Sao Paulo University Craniofacial Anomalies Rehabilitation Hospital/Bauru Campus. Address for correspondence: Rua Ivane de Andrade Almeida 1-86 Condomínio Villagio 17018-825 Bauru SP.

This paper was submitted to the RBORL - SGP (Publications Management System) on 11/10/2005 and approved on 5/5/2006 15:47:35.

Paper submitted to the ABORL-CCF SGP (Management Publications System) on March 11th, 2005 and accepted for publication on June 20 th, 2006. Cod. 1501.
} 


\section{INTRODUCTION}

\section{Cochlear pathophysiology and dead regions in the coch- lea}

The cochlear region where internal ciliated cells (ICC) are injured, inactive or absent, and the neurons that innervate this region are inactive or even degenerate, has been named dead region of the cochlea, or dead region. ${ }^{1-3}$

Although the dead region concept was elaborated many years ago by Gravendeel and Plomp, ${ }^{4}$ it generated little medical interest until Moore et al., in recent papers on this topic, brought the term back to use. This author describes dead regions based on the frequency of injured ICCs and/or neurons belonging to the dead region in question. $.3,6$

Audiogram configurations have also been considered as evidence or dead regions, such as sloping audiograms, where thresholds worsen abruptly with increasing pitch (over $50 \mathrm{~dB}$ /octave) at high frequencies. Hearing losses of 40-50 dB at low frequencies and hearing close to normal in medium and high frequencies may suggest dead regions at low frequencies. This may also be the case when there is hearing loss over $50 \mathrm{~dB}$ at low frequencies with improved thresholds at higher frequencies. A U-shaped audiogram, with better hearing at low and high frequencies and a dead region at middle frequencies, is rare and generally does not interfere significantly with speech recognition. Residual hearing allows good recognition, meaning that some of these cases do not require hearing aids (individual sound amplification devices). ${ }^{5}$

Huss et al. investigated pure tone perception in subjects with and without dead regions diagnosed by psychophysical tuning curves and the threshold-equalizing-noise (TEN) test, in which participants were asked to score the sharpness of a pure tone on a scale from sharp (1) to noisy (7). The authors concluded that the pure tone subjective impression of sharpness is not a consistent indicator of dead regions in the cochlea, as higher scores were seen not only in ears with dead regions but also in normal ears at similar frequencies and at higher thresholds. ${ }^{7}$

It is clear that patient reports or the audiogram by themselves are not sufficient to establish or exclude the presence and extension of dead regions. Thus, masking has been used in some studies to investigate this condition in greater detail.

\section{Assessment of dead regions in the cochlea}

The investigation of dead regions uses ipsilateral masking, in which the test signal and the masking noise are presented to the same ear. The idea is to raise the threshold of non-tested frequencies so that they do not respond to excitation diffusion of the signal that is being tested at a specific frequency.

Moore et al. developed the Threshold-EqualizingNoise test to investigate the presence of dead regions. Although masking is defined as a procedure used in audiological evaluation, and not a test in itself, TEN is considered a test by its authors. It is based on the detection of pure tones presented simultaneously with a wide band noise (TEN) which produces practically the same level of masking (measured in dBNPS) throughout audiogram frequencies $(250 \mathrm{~Hz}$ to $10,000 \mathrm{~Hz})$ in normal hearing or hearing-impaired individuals with no dead regions., 3,5

In Brazil Eguti investigated the efficiency of the masking technique using white noise to identify dead regions in the cochlea of 32 adult individuals that presented acquired sensorineural or mixed hearing loss and a sloping audiometric configuration. Moore's $\mathrm{s}^{5}$ criteria and masking test results using white noise showed a strong correlation (kappa index of agreement $=96.1 \%)$. The author concluded that the masking technique using white noise is a reliable and simple test for routine use in a clinical setting to test for dead regions in the cochlea for cases of acquired sensorineural hearing loss in a sloping configuration. ${ }^{8}$

The diagnosis of dead regions in the cochlea is important in medical practice, as studies have shown that its presence limits the use of hearing aids, since these regions respond minimally or not at all to sound amplification. $., 6,9$

\section{OBJECTIVE}

Our aim was to use the TEN test to investigate the presence of dead regions in the cochlea in subjects with sensorineural hearing loss seen at the Center for Audition, Vision and Language Disorders (CEDALVI) of the Sao Paulo University Craniofacial Anomalies Rehabilitation Hospital/Bauru Campus (HRAC-USP-Bauru).

\section{MATERIAL AND METHODS}

This study was undertaken at the CEDALVI/HRAC/ USP-Bauru between August 2003 and February 2004.

\section{CASES}

\section{Profile}

According to the routine at CEDALVI, patients are monitored by a multidisciplinary audiology team. Participants were assessed by an ENT specialist who did otoscopy and decided whether conditions were appropriate for the TEN test, namely intact tympanic membranes and no external and middle ear compromise.

Cases for this study are shown on Table 1. 
Table 1. Number of subjects, ears and audiograms for groups G1, G2 and G3.

\begin{tabular}{cccc}
\hline Groups & Number of subjects & Number of ears & Audiogram \\
\hline G1 & 5 & 10 & $\begin{array}{c}\text { normal } \\
(\leq 15 \mathrm{dBNA}) \\
\text { mild flat sen- } \\
\text { sorineural } \\
\text { hearing loss } \\
\text { moderate to }\end{array}$ \\
G3 & 9 & 15 & $\begin{array}{c}\text { mevere sloping } \\
\text { sensorineural } \\
\text { hearing loss }\end{array}$ \\
\hline TOTAL & 43 & 76 & \\
\hline
\end{tabular}

\section{Selection criteria}

The selection of subjects was based on the following inclusion criteria:

a) G1: pure tone air conduction thresholds within normal limits ( $\leq 15 \mathrm{dBNA})$;

b) G2: mild flat configuration sensorineural hearing loss (Davis and Silverman); ${ }^{10}$

c) G3: moderate to severe sloping sensorineural hearing loss.

\section{General ethical aspects}

Participants signed a free informed consent form approved by the Research Ethics Committee of the HRACUSP, number 263/2004-UEP-CEP, agreeing to take part in the study and to allow publication of collected data.

\section{METHODS}

\section{Instrument and Procedure}

a) TEN biological calibration

We used the Veniar ${ }^{11}$ biological calibration technique and the procedure consisted of simultaneously and ipsilaterally (through the same earphone) presenting a pure tone at an initial intensity of $30 \mathrm{dBNPS}$ (minimal audiometer setting) and noise (TEN), which was increased in $5 \mathrm{~dB}$ steps until it masked the test stimulus.

b) TEN test

The TEN test was applied using a two-channel audiometer, PAC 2000 model (Acustica Orlandi) with a TDH-39 P supra-aural earphone and a Sony Discman digital MEGA BASS model, in a soundproofed cabin. Moore et al. (2000) recorded the test on a CD with noise (TEN) on one channel and a digitally generated test signal (pure tone) recorded on another CD channel. This was done to simplify and increase the clinical availability of the TEN test.

The following test procedures were undertaken:

(1) the CD player output plug was connected to the audiometer right and left input socket (usually used for tape input). The first CD track is a calibrating tone, which was played to adjust the audiometer right and left channel VU meters at $-5 \mathrm{~dB}$, or $5 \mathrm{~dB}$ below zero; this was done to calibrate the signal-to-noise ratio, or the intensity difference between the pure tone and noise. For the remaining tracks the noise intensity level in the right channel was read as $10 \mathrm{~dB}$ better than the indicated level on the dial, and the left channel pure tone was read as $10 \mathrm{~dB}$ worse. We could then adjust the audiometer controls for the desired intensities for pure tones and noise. Thus, if the pure tone and noise intensities were 50 and 40dBNPS, the dial was adjusted to 40 and $50 \mathrm{~dB}$, respectively.

(2) Air conduction absolute thresholds (ATs) and masked thresholds (MTs) were obtained by manual audiometry, according to Carhart and Jerger, ${ }^{7}$ with stimuli controlled on the audiometer to which the CD was attached. ATs were assessed as dBNPS at frequencies of 250, 500, 1,000, 2,000, 3,000, 4,000, 6,000, and 8,000 Hz, using test pure tones recorded on the CD left channel. This procedure was applied separately to each ear; there was no need to use contralateral masking, as in no case the opposite ear had a sufficient threshold to respond for the tested ear.

(3) MTs with noise (TEN) were assessed at the same frequencies, according to the audiometric configuration, with both channels operating. The TEN intensity depended on the AT by frequency in each patient, and was $10 \mathrm{~dB}$ better than the AT, that is, if the AT was $50 \mathrm{~dB}$, the TEN was adjusted to $40 \mathrm{~dB}$ on the dial.

(4) If the MT was only $5 \mathrm{~dB}$ worse than the AT, the test was repeated with higher masking noise intensity.

\section{Data analysis}

\section{Criteria for result analysis}

a) Biological calibration of the TEN

The minimal effective masking level considered was the amount of noise (TEN) that was needed to eliminate the test tone (30 dBNPS) for each frequency.

b) TEN test

According to Moore et al.'s ${ }^{3}$ criteria, dead regions in the cochlea were suggested when, at a specific frequency, the MT was at least worse by $10 \mathrm{~dB}$ than the AT and 10 $\mathrm{dB}$ worse than the masking noise (TEN). Absence of dead regions was indicated if the MT was equal to the AT. The result was considered as inconclusive if the difference between the AT and the MT was $5 \mathrm{~dB}$, or if intensity on the audiometer was not sufficient to assess the MT.

c) Statistical method

The following statistical tests were used: $t$ test (test to compare two paired samples, or the t-student test), and Spearman's rank correlation coefficient. The null hypothesis rejection value (Ho) was 5\%. 


\section{RESULTS}

\section{Study of the variation of absolute thresholds using the TEN}

Table 2 shows the results for absolute thresholds and threshold values obtained using TEN in group G1.

As seen on Table 2, the TEN value needed to eliminate the test tone (AT) was, on average, close to the AT for all frequencies, demonstrating the effectiveness of masking, as the minimal stimulus intensity difference on the dial was $5 \mathrm{~dB}$ and the standard deviation ranged from 2.42 to $3.54 \mathrm{~dB}$.

Tables 3 and 4 show the results for groups G2 e G3.

According to Moore et al.' $\mathrm{s}^{3}$ criteria, we saw no dead regions in all tested ears shown on Table 3. Ears 7 and 11 , at $6 \mathrm{kHz}$ and $3 \mathrm{kHz}$, had MTs $5 \mathrm{~dB}$ worse than the AT. Auditory discomfort did not allow investigation at $8 \mathrm{KHz}$ in ear 3. The test for dead regions was considered inconclusive for these three ears.

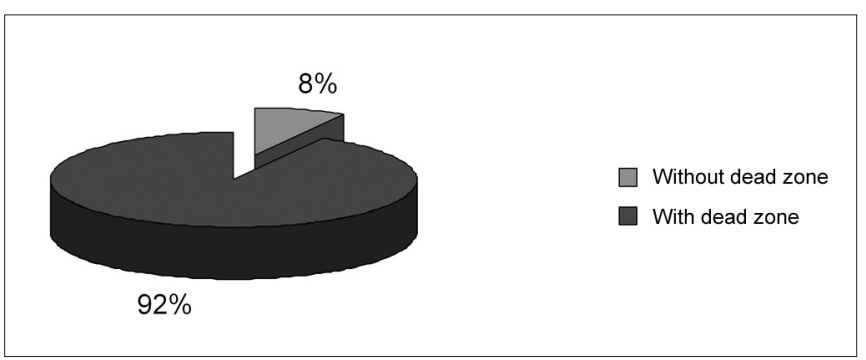

Figure 1. Frequency of occurrence of dead regions in 76 group G3 ears.

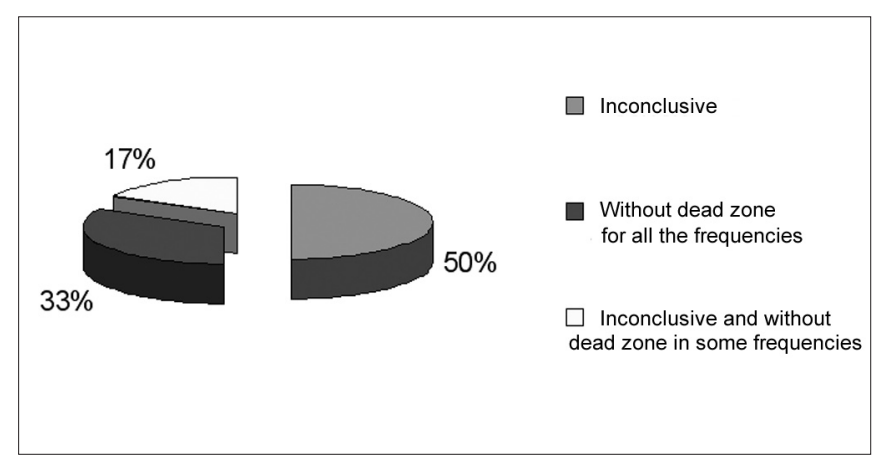

Figure 2. Frequency of occurrence of inconclusive results and with no dead regions in 6 ears with results not indicating dead regions in group G3.

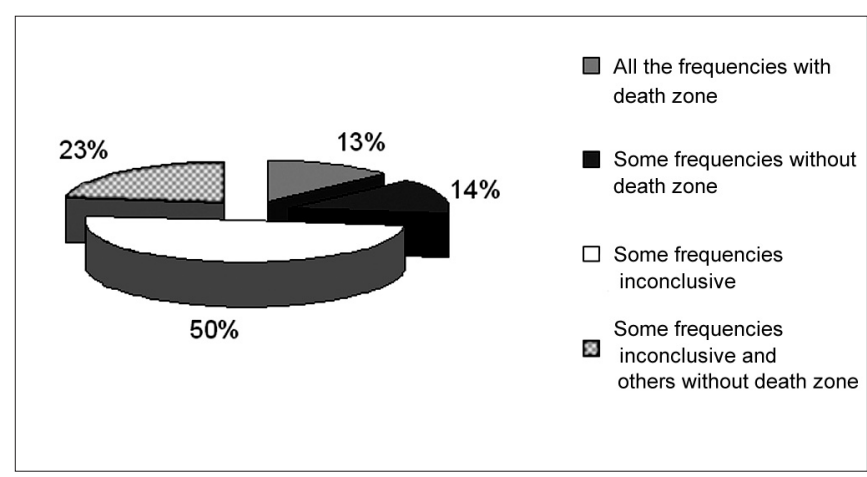

Figure 3. Frequency of occurrence of inconclusive results and with no dead regions in 70 ears with results suggesting dead regions in group G3.

A frequency of occurrence analysis was made in group G3 (Table 4), as shown on Figures 1, 2 and 3.

\section{Statistical analysis}

\section{Comparison of the difference between MTs and ATs by frequency}

Statistical analysis using the $t$ test $(\mathrm{Ho}=\mathrm{A}=\mathrm{B}$ and $\mathrm{H} 1=\mathrm{B}>\mathrm{A}$ ) was applied to group $\mathrm{G} 3$, in which the tests suggested dead regions in the cochlea according to Moore et al.'s $\mathrm{s}^{3}$ criteria. The aim was to check whether dead regions were more frequent at higher frequencies, defined by the difference between the MT and the AT, in cases of sloping sensorineural hearing loss. An added difference between the MT and the AT was assessed at high frequencies. According to our statistical analysis, the difference between the MT and the AT at $8 \mathrm{kHz}$ was not significantly higher than the difference between the MT and the AT at $1 \mathrm{kHz}$. The same result applied to the difference at $6 \mathrm{kHz}$ and $1 \mathrm{kHz}, 8 \mathrm{kHz}$ and $6 \mathrm{kHz}$, and $4 \mathrm{kHz}$ and $3 \mathrm{kHz}$. The difference between the MT and the AT was significantly higher at $2 \mathrm{kHz}$ compared to $1 \mathrm{kHz}$.

\section{Comparison of the difference between MTs and ATs by frequency}

The $\mathrm{t}$ test $(\mathrm{Ho}=\mathrm{A}=\mathrm{B}$ e $\mathrm{H} 1=\mathrm{B}>\mathrm{A})$ was applied to group G3 to check whether there was any significant difference between the MT and the AT after applying the TEN test. No significant difference was seen between the MT and the AT at all frequencies.

\section{Correlation of the difference between MTs and ATs by frequency \\ Spearman's rank correlation coefficient $(\mathrm{rs})(\mathrm{Ho}=\mathrm{rs}$ $=0$ and $\mathrm{H} 1=\mathrm{rs} \neq 0$ ) was calculated to check whether dead}


Table 2. TEN values (in dBNPS) needed to eliminate the test tone (AT) in 10 group 1 ears (G1).

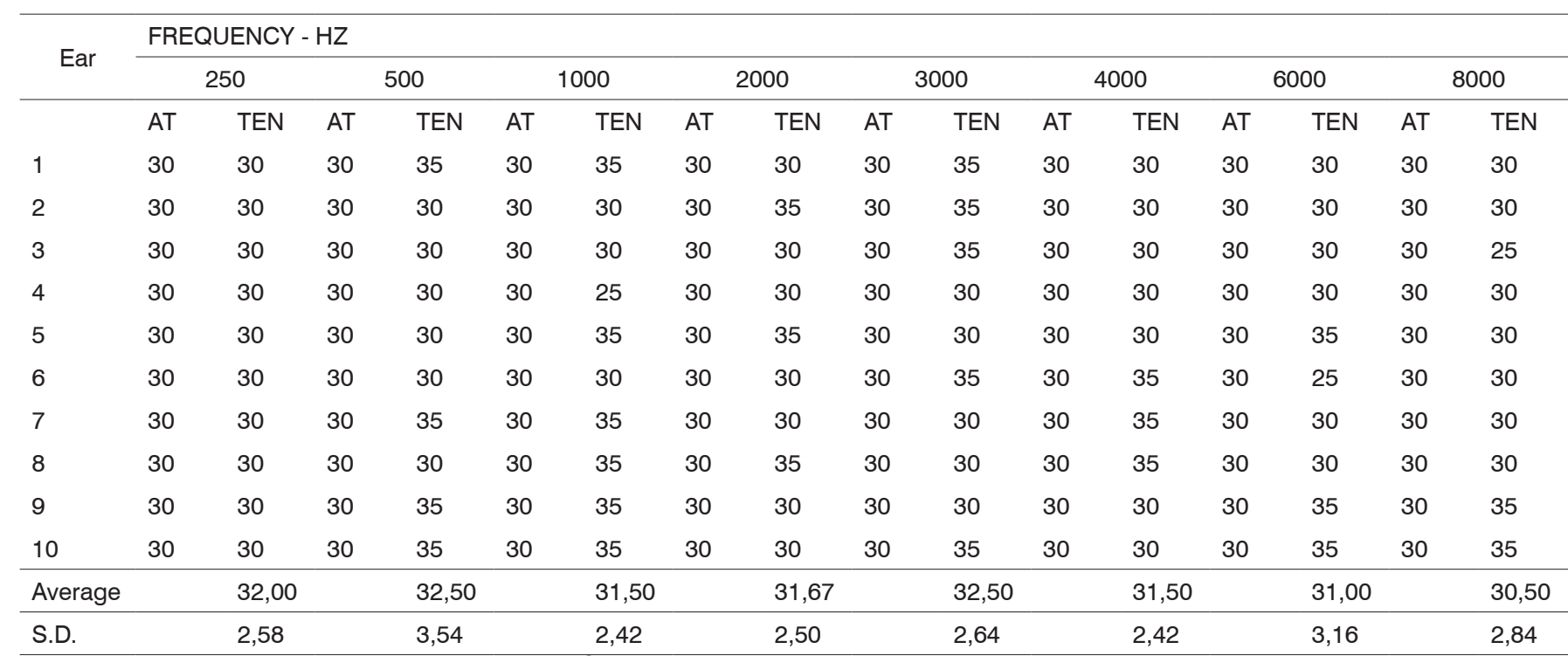

Legend: AT absolute threshold TEN masking noise S.D. standard deviation

Table 3. AT and MT values (in dBNPS) with TEN at $10 \mathrm{~dB}$ better than the AT, obtained in 15 group 2 ears (G2).

\begin{tabular}{|c|c|c|c|c|c|c|c|c|c|c|c|c|c|c|c|c|}
\hline \multirow{3}{*}{ Ear } & \multicolumn{16}{|c|}{ FREQUENCY - HZ } \\
\hline & \multicolumn{2}{|c|}{250} & \multicolumn{2}{|c|}{500} & \multicolumn{2}{|c|}{1000} & \multicolumn{2}{|c|}{2000} & \multicolumn{2}{|c|}{3000} & \multicolumn{2}{|c|}{4000} & \multicolumn{2}{|c|}{6000} & \multicolumn{2}{|c|}{8000} \\
\hline & AT & MT & AT & MT & AT & MT & AT & MT & AT & MT & AT & MT & AT & MT & AT & MT \\
\hline 1 & 55 & & 55 & & 65 & 65 & 70 & 70 & 70 & 70 & 70 & 70 & 85 & 85 & 100 & 100 \\
\hline 2 & 55 & & 55 & & 65 & 65 & 75 & 75 & 70 & 70 & 80 & 80 & 100 & 100 & 100 & 100 \\
\hline 3 & 55 & & 50 & & 50 & 50 & 55 & 55 & 70 & 70 & 85 & 85 & 95 & 95 & 100 & desc \\
\hline 4 & 70 & & 60 & & 45 & 45 & 50 & 50 & 75 & 75 & 85 & 85 & 95 & 95 & 90 & 90 \\
\hline 5 & 40 & & 50 & & 65 & 65 & 70 & 70 & 75 & 75 & 85 & 85 & 85 & 85 & 95 & 95 \\
\hline 6 & 55 & & 60 & & 60 & 60 & 75 & 75 & 70 & 70 & 75 & 75 & 80 & 80 & 95 & 95 \\
\hline 7 & 75 & & 75 & & 80 & 80 & 80 & 80 & 80 & 80 & 85 & 85 & 100 & 105 & 100 & 100 \\
\hline 8 & 50 & & 55 & & 60 & 60 & 65 & 65 & 60 & 60 & 65 & 65 & 85 & 85 & 75 & 75 \\
\hline 9 & 45 & & 50 & & 55 & 55 & 65 & 65 & 70 & 70 & 70 & 70 & 85 & 85 & 90 & 90 \\
\hline 10 & 70 & & 60 & & 75 & 75 & 80 & 80 & 65 & 65 & 80 & 80 & 75 & 75 & 85 & 85 \\
\hline 11 & 80 & & 65 & & 85 & 85 & 70 & 70 & 60 & 65 & 70 & 70 & 85 & 85 & 90 & 90 \\
\hline 12 & 50 & & 60 & & 65 & 65 & 80 & 80 & 85 & 85 & 95 & 95 & 90 & 90 & 85 & 85 \\
\hline 13 & 30 & & 30 & & 30 & 30 & 40 & 40 & 50 & 50 & 55 & 55 & 55 & 55 & 60 & 60 \\
\hline 14 & 30 & & 30 & & 30 & 30 & 30 & 30 & 65 & 65 & 75 & 75 & 90 & 90 & 75 & 75 \\
\hline 15 & 60 & & 45 & & 55 & 55 & 75 & 75 & 85 & 85 & 80 & 80 & 100 & 100 & 90 & 90 \\
\hline
\end{tabular}

Legend: disc auditory discomfort, threshold not assessed AT absolute threshold

MT masked threshold with TEN NR no response 
Table 4. AT and MT values (in dBNPS) with TEN at $10 \mathrm{~dB}$ better than the AT, obtained in 76 group 3 ears (G3).

\begin{tabular}{|c|c|c|c|c|c|c|c|c|c|c|c|c|c|c|c|c|}
\hline \multirow{3}{*}{ Ear } & \multicolumn{16}{|c|}{ FREQUENCY - HZ } \\
\hline & \multicolumn{2}{|c|}{250} & \multicolumn{2}{|c|}{500} & \multicolumn{2}{|c|}{1000} & \multicolumn{2}{|c|}{2000} & \multicolumn{2}{|c|}{3000} & \multicolumn{2}{|c|}{4000} & \multicolumn{2}{|c|}{6000} & \multicolumn{2}{|c|}{8000} \\
\hline & AT & MT & AT & MT & AT & MT & AT & MT & AT & MT & AT & MT & AT & MT & AT & MT \\
\hline 2 & 30 & & 30 & & 30 & 40 & 40 & 50 & 55 & 55 & 60 & 70 & 85 & 95 & 95 & 105 \\
\hline 3 & 40 & & 40 & & 35 & 35 & 70 & 80 & 80 & 90 & 85 & 95 & 100 & disc & 90 & disc \\
\hline 5 & 45 & & 35 & & 30 & 30 & 50 & 60 & 85 & 95 & 100 & Disc & 110 & disc & NR & --- \\
\hline 6 & 35 & & 35 & & 35 & 35 & 75 & 85 & 90 & disc & 105 & Disc & 110 & disc & NR & --- \\
\hline 7 & 40 & & 50 & & 70 & 80 & 75 & 85 & 75 & 85 & 85 & 95 & 90 & disc & 95 & disc \\
\hline 8 & 35 & & 30 & & 40 & 50 & 60 & 70 & 90 & 100 & 90 & 100 & 100 & disc & NR & --- \\
\hline 9 & 30 & & 30 & & 30 & 40 & 80 & 90 & 85 & 95 & 80 & 90 & 90 & 100 & 80 & 90 \\
\hline 13 & 40 & & 35 & & 85 & 95 & NR & & 115 & NR & 115 & NR & 115 & NR & 95 & NR \\
\hline 14 & 30 & & 30 & & 75 & 85 & 110 & NR & NR & NR & NR & --- & NR & --- & NR & --- \\
\hline 15 & 30 & & 40 & & 55 & 65 & 60 & 70 & 60 & 70 & 75 & 85 & 75 & 85 & 95 & 105 \\
\hline 16 & 30 & & 35 & & 50 & 50 & 65 & 75 & 60 & 70 & 75 & 85 & 75 & 85 & 95 & 105 \\
\hline 17 & 40 & & 40 & & 70 & 80 & 70 & 80 & 80 & 90 & 95 & Disc & 85 & 90 & 95 & disc \\
\hline 18 & 30 & & 30 & & 50 & 60 & 75 & 85 & 80 & 90 & 100 & Disc & 90 & 100 & 90 & 100 \\
\hline 19 & 35 & & 40 & & 40 & 50 & 75 & 85 & 65 & 75 & 75 & 85 & 85 & 95 & 90 & 100 \\
\hline 20 & 35 & & 40 & & 45 & 55 & 70 & 80 & 70 & 80 & 80 & 90 & 100 & disc & 110 & disc \\
\hline 27 & 60 & & 65 & & 65 & 75 & 95 & 105 & 90 & 100 & NR & --- & NR & --- & NR & --- \\
\hline 28 & 45 & & 50 & & 65 & 75 & 85 & 95 & 90 & 100 & 100 & 110 & NR & --- & NR & --- \\
\hline 29 & 30 & & 40 & & 55 & 60 & 75 & 85 & 80 & 90 & 75 & 85 & 95 & 100 & 105 & disc \\
\hline 30 & 30 & & 40 & & 55 & 65 & 70 & 80 & 70 & 80 & 70 & 80 & 95 & 100 & 95 & 105 \\
\hline 31 & 30 & & 30 & & 30 & 40 & 60 & 70 & 65 & 75 & 65 & 75 & 85 & 95 & 80 & 90 \\
\hline 32 & 30 & & 30 & & 30 & 40 & 60 & 70 & 70 & 80 & 80 & 90 & 60 & 65 & NR & --- \\
\hline 33 & 35 & & 55 & & 75 & 85 & 60 & 70 & 85 & 95 & 80 & 90 & 90 & 100 & NR & --- \\
\hline 34 & 30 & & 55 & & 70 & 75 & 75 & 85 & 80 & 90 & 85 & 90 & 90 & 95 & 105 & 115 \\
\hline 35 & 30 & & 45 & & 60 & 70 & 80 & 85 & 75 & 80 & 75 & 85 & 110 & NR & 110 & NR \\
\hline 36 & 35 & & 50 & & 60 & 65 & 70 & 75 & 70 & 75 & 85 & 90 & 105 & disc & 110 & NR \\
\hline 37 & 30 & & 30 & & 35 & 35 & 70 & 80 & 70 & 80 & 80 & 90 & 80 & 90 & 85 & 95 \\
\hline 38 & 30 & & 30 & & 35 & 35 & 70 & 80 & 80 & 90 & 80 & 90 & 90 & 100 & 105 & 115 \\
\hline 39 & 35 & & 30 & & 50 & 55 & 90 & 95 & 105 & NR & 115 & NR & 110 & NR & 115 & NR \\
\hline 40 & 30 & & 30 & & 35 & 45 & 85 & 90 & 95 & NR & 100 & 105 & 110 & NR & 110 & NR \\
\hline 41 & 35 & & 40 & & 60 & 65 & 70 & 75 & 65 & 70 & 85 & 95 & 100 & 105 & 105 & NR \\
\hline
\end{tabular}


Continuation Table 4. AT and MT values (in dBNPS) with TEN at 10dB better than the AT, obtained in 76 group 3 ears (G3)..

\begin{tabular}{|c|c|c|c|c|c|c|c|c|c|c|c|c|c|c|c|c|}
\hline \multirow{3}{*}{ Ear } & \multicolumn{16}{|c|}{ FREQUENCY - HZ } \\
\hline & \multicolumn{2}{|c|}{250} & \multicolumn{2}{|c|}{500} & \multicolumn{2}{|c|}{1000} & \multicolumn{2}{|c|}{2000} & \multicolumn{2}{|c|}{3000} & \multicolumn{2}{|c|}{4000} & \multicolumn{2}{|c|}{6000} & \multicolumn{2}{|c|}{8000} \\
\hline & AT & MT & AT & MT & AT & MT & AT & MT & AT & MT & AT & MT & AT & MT & AT & MT \\
\hline 42 & 50 & & 55 & & 75 & 85 & 110 & NR & NR & & 115 & NR & NR & --- & NR & --- \\
\hline 43 & 35 & & 50 & & 75 & 85 & 75 & 80 & 75 & 80 & 90 & 95 & 95 & 105 & 105 & 115 \\
\hline 44 & 40 & & 35 & & 50 & 50 & 55 & 60 & 60 & 70 & 75 & 85 & 90 & 100 & 105 & NR \\
\hline 45 & 50 & & 30 & & 30 & 35 & 30 & 35 & 60 & 70 & 70 & 75 & 80 & 90 & NR & --- \\
\hline 46 & 35 & & 45 & & 60 & 65 & 75 & 80 & 90 & 95 & 105 & NR & 110 & NR & 115 & $\mathrm{NR}$ \\
\hline 47 & 30 & & 40 & & 60 & 65 & 70 & 75 & 75 & 85 & 105 & 115 & 115 & NR & 115 & NR \\
\hline 48 & 30 & & 30 & & 60 & 60 & 80 & 85 & 95 & 105 & 105 & NR & NR & & 105 & NR \\
\hline 49 & 30 & & 30 & & 55 & 65 & 90 & 100 & 95 & 105 & 105 & NR & 100 & NR & NR & --- \\
\hline 50 & 30 & & 30 & & 30 & 30 & 65 & 75 & 80 & 90 & 80 & 90 & 80 & 90 & 90 & 100 \\
\hline 51 & 30 & & 30 & & 30 & 30 & 65 & 70 & 85 & 90 & 85 & 95 & 105 & 115 & 105 & NR \\
\hline 52 & 45 & & 45 & & 55 & 55 & 90 & 90 & 85 & 85 & 95 & 95 & 90 & 100 & 90 & 90 \\
\hline 53 & 35 & & 40 & & 50 & 50 & 70 & 70 & 75 & 85 & 85 & 95 & 95 & 105 & 110 & $\mathrm{NR}$ \\
\hline 54 & 40 & & 55 & & 65 & 75 & 70 & 80 & 85 & 95 & 95 & 105 & 95 & 105 & 110 & NR \\
\hline 55 & 35 & & 40 & & 45 & 45 & 75 & 75 & 75 & 75 & 70 & 75 & 85 & 85 & 90 & 100 \\
\hline 56 & 35 & & 35 & & 40 & 50 & 65 & 75 & 70 & 70 & 80 & 80 & 85 & 85 & 100 & 100 \\
\hline 57 & 35 & & 30 & & 40 & 40 & 65 & 75 & 70 & 75 & 80 & 80 & 105 & disc & 100 & disc \\
\hline 58 & 35 & & 30 & & 35 & 45 & 50 & 50 & 55 & 55 & 60 & 60 & 75 & 75 & 80 & 90 \\
\hline 59 & 35 & & 30 & & 30 & 30 & 45 & 45 & 50 & 50 & 70 & 70 & 80 & 90 & 100 & 105 \\
\hline 60 & 50 & & 40 & & 30 & 30 & 35 & 35 & 45 & 45 & 60 & 65 & 90 & 95 & 105 & disc \\
\hline 61 & 30 & & 40 & & 65 & 65 & 75 & 75 & 70 & 70 & 70 & 70 & 70 & 70 & 65 & 65 \\
\hline 62 & 30 & & 35 & & 65 & 65 & 85 & 85 & 70 & 70 & 80 & 80 & 70 & 70 & 70 & 70 \\
\hline 63 & 35 & & 35 & & 60 & 60 & 85 & 90 & 90 & 100 & 100 & 105 & NR & --- & NR & --- \\
\hline 64 & 35 & & 40 & & 60 & 70 & 75 & 85 & 70 & 75 & 80 & 85 & 85 & 90 & 110 & NR \\
\hline 65 & 45 & & 55 & & 50 & 60 & 65 & 75 & 65 & 70 & 70 & 75 & 95 & 100 & 100 & disc \\
\hline 66 & 45 & & 45 & & 55 & 60 & 75 & 75 & 80 & 90 & 80 & 85 & 115 & NR & 115 & NR \\
\hline 67 & 35 & & 30 & & 70 & 80 & 85 & 90 & 85 & 85 & 90 & 100 & 95 & 105 & 110 & NR \\
\hline 68 & 30 & & 30 & & 30 & 30 & 50 & 50 & 45 & 55 & 60 & 70 & 100 & 110 & 95 & 105 \\
\hline 69 & 50 & & 45 & & 50 & 60 & 40 & 50 & 70 & 80 & 85 & 95 & 110 & NR & 105 & NR \\
\hline 70 & 30 & & 30 & & 30 & 30 & 60 & 70 & 55 & 65 & 75 & 85 & 75 & 85 & 110 & NR \\
\hline 71 & 35 & & 40 & & 35 & 45 & 50 & 60 & 55 & 65 & 75 & 85 & 100 & 110 & NR & --- \\
\hline 72 & 45 & & 55 & & 70 & 80 & 75 & 85 & 70 & 80 & 75 & 85 & 110 & NR & 115 & NR \\
\hline 73 & 50 & & 45 & & 60 & 70 & 65 & 75 & 70 & 80 & 85 & 95 & 95 & 105 & 110 & NR \\
\hline 74 & 35 & & 35 & & 60 & 70 & 70 & 80 & 80 & 90 & 85 & 95 & 95 & 105 & 90 & 100 \\
\hline 75 & 30 & & 30 & & 65 & 75 & 75 & 85 & 80 & 90 & 90 & 100 & 105 & disc & 115 & disc \\
\hline 76 & 30 & & 30 & & 65 & 75 & 70 & 80 & 75 & 85 & 75 & 85 & 115 & NR & 115 & NR \\
\hline
\end{tabular}

Legend: AT absolute threshold MT masked threshold with TEN NR no response disc presence of discomfort, threshold not assessed 
regions could be correlated with different frequencies, in cases of sloping sensorineural hearing loss. Differences between the MT and the AT were reported by frequency in group $\mathrm{G} 3$.

The correlation is significant only for differences between the MT and the AT between frequencies of 1 $\mathrm{kHz}$ and $2 \mathrm{kHz}, 6 \mathrm{kHz}$ and $8 \mathrm{kHz}$, and $3 \mathrm{kHz}$ and $4 \mathrm{kHz}$ for group G3. The correlation is not significant between frequencies of $1 \mathrm{kHz}$ and $8 \mathrm{kHz}$, and $1 \mathrm{kHz}$ and $6 \mathrm{kHz}$.

\section{DISCUSSION}

A $5 \mathrm{~dB}$ variation over the absolute auditory threshold following presentation of TEN was considered as indicating the absence of dead regions in the cochlea. This variation was observed in the biological calibration procedure for ten normal ears (group G1; Table 2), and in the TEN test on fifteen ears with moderate flat hearing loss (group G2; Table 3) in which this difference was seen on only two ears. Moore et al. ${ }^{3}$ reported a $2 \mathrm{~dB}$ to $3 \mathrm{~dB}$ variation in the auditory thresholds, standardizing the $5 \mathrm{~dB}$ difference as an inconclusive result for identifying dead regions. Eguti ${ }^{8}$ reported a $5 \mathrm{~dB}$ variation on the absolute auditory threshold by presenting white noise during the biological calibration procedure to ten normal listeners.

According to Moore et al.' $\mathrm{s}^{3}$ criteria, which also considers a sloping audiometric configuration as evidence of dead regions, we found seventy ears out of seventysix ears in group G3 with results suggesting dead regions (Figure 1). All of the group G3 audiograms had at least a $50 \mathrm{~dB}$ difference per octave between two of all tested frequencies. Results showed a significant difference between the MT and the AT for all frequencies.

Statistical analysis showed that the difference between the MT and the AT was higher only for $2 \mathrm{kHz}$ when compared to $1 \mathrm{kHz}$. Moore et al. ${ }^{3}$ defines a $10 \mathrm{~dB}$ difference between the MT and the AT as indicating dead regions in the cochlea. Moore et al.'s papers, ${ }^{3,5,6,13,14}$ on dead regions at high frequency in sloping sensorineural hearing loss have showed that generally the estimated dead region limit frequency starts at $2 \mathrm{kHz}$, which would justify the difference between $2 \mathrm{kHz}$ and $1 \mathrm{kHz}$ we found. Moore ${ }^{13}$ recommended that in sloping hearing loss the TEN test should be applied at $2 \mathrm{kHz}$ and upwards, or in cases where the threshold change would imply in a progression of the degree of hearing loss from mild or moderate to severe.

Equality relations between $8 \mathrm{kHz}$ and $6 \mathrm{kHz}$, and 4 $\mathrm{kHz}$ and $3 \mathrm{kHz}$ could be associated with the closeness of theses frequencies; a larger difference has been observed from $2 \mathrm{kHz}$ upwards, which suggests constancy in the variation of masked thresholds for high frequencies.

Inconclusive results were seen more frequently at frequencies of $6 \mathrm{kHz}$ and $8 \mathrm{kHz}$ (Table 4), mostly due to discomfort, lack of response, or insufficient masking intensity. These results may have influenced the lack of a difference between MT and AT relations for frequencies of $8 \mathrm{kHz}$ and $1 \mathrm{kHz}$, and $6 \mathrm{kHz}$ and $1 \mathrm{kHz}$, although Moore et al. ${ }^{3}$ states that unresponsive frequencies for the most intense stimulus level in the audiometer are strongly indicative of dead regions in the cochlea.

Spearman's rank correlation coefficient was calculated for group G3 to check whether dead regions could be associated with different frequencies in sloping sensorineural hearing loss. There was no significant correlation between distant frequencies, such as between $1 \mathrm{kHz}$ and $8 \mathrm{kHz}$, and $1 \mathrm{kHz}$ and $6 \mathrm{kHz}$. For close frequencies, such as $1 \mathrm{kHz}$ and $2 \mathrm{kHz}$, and $3 \mathrm{kHz}$ and $4 \mathrm{kHz}$ for $\mathrm{G} 3$, and 6 $\mathrm{kHz}$ and $8 \mathrm{kHz}$, there was a significant correlation, which could be explained by the excitation diffusion phenomenon in the case of dead regions within the nervous fiber response area. According to Henderson et al., ${ }^{15}$ Bess and Humes,${ }^{16}$ and Lent, ${ }^{17}$ any frequency and intensity combination represented within this area produces a nervous fiber response. However, when the stimulus is moved upwards or downwards from that frequency, the intensity has to be raised to activate the fiber. In sensorineural hearing loss, where tuning curves are widened, excitation would be distributed more widely close to the threshold in which normal hearing would take place (Evans ${ }^{18}$ ).

Figure 1 shows that $92 \%$ of seventy-six tested ears had results indicating dead regions, which agrees with previous results that suggest a significant prevalence of dead regions in individuals with sloping sensorineural hearing loss. $3,5,6,13,14,9,19$ Summers et al. ${ }^{19}$ used TEN and psychophysical tuning curves (PTC) to assess eighteen ears with moderate to severe sloping sensorineural hearing loss. Results from both tests were similar, showing dead regions in six ears and no dead regions in four ears out of ten ears. Results for the remaining eight ears diverged in one or more frequencies in the TEN test and the PTC, where TEN test results suggested dead regions and PTC did not. The authors explained that the difficulty in listening to noise experienced by individuals with sensorineural hearing loss could be related to the loss of filtering activity due to widened tuning curves, which would raise threshold levels on the TEN test. On PTC, as the noise intensity is very close to the threshold, there would be no difficulty, as the signal-to-noise ratio would be larger. According to Moore et al. ${ }^{3}$ results between PTC and the TEN test were similar in 20 ears with sensorineural hearing loss. Eguti ${ }^{8}$ observed a strong agreement (kappa index of agreement =96.1\%) between Moore's (2001) criteria and masking test results using white noise.

White noise tests for dead regions, however, require further validation, such as comparisons with PTC results. PTC is a proven and internationally accepted method to study cochlear tuning curves (Halpin ${ }^{20}$ ).

Summers et al. ${ }^{19}$ used a fixed TEN level of 70,85 or $90 \mathrm{~dB} / \mathrm{ERB}$, which for certain thresholds, would be a 
negative signal-to-noise ratio. We fixed the TEN level at a signal-to-noise ratio of $+10 \mathrm{~dB}$, so that there would be no noise filter difficulties.

The TEN test described by Moore et al. ${ }^{3}$ is a simple procedure based on the routine investigation of air conduction pure tone thresholds. However, it does not use a dBNA as an intensity value measure, which is conventionally used clinically in audiogram reports. The TEN value is expressed as $\mathrm{dB} / \mathrm{ERB}$, and was calibrated to be equivalent to dBNPS. Therefore, the clinician has to first investigate air conduction pure tone thresholds in dBNA by the audiometer stimulus and then convert it into dBNPS, which requires additional time in the audiological diagnosis routine. An option is to use pure tones in dBNPS recorded on a TEN test CD, as adopted in our study. However, this procedure is feasible only when the aim is to investigate the presence of dead regions, which in itself can only be defined following an audiogram result that shows configuration suggesting dead regions, such as an inter-octave difference equalt to or higher than 50dB.5 Moore ${ }^{21}$ also recommended that the TEN test be applied in individuals that report receiving the pure tone as "noise, and not a whistle," for users of hearing aids that report no benefits with amplification, to define an indication for short-insertion cochlear implants, and in occupational audiometry as a legal support in cases where high frequencies could be more damaged than suggested by conventional audiometry.

During the TEN test dial readings can by somewhat confusing; according to Moore el al.' $\mathrm{s}^{3}$ recommendations, the right channel noise intensity level should be read as 10 $\mathrm{dB}$ better than the level indicated on the dial, and that the left channel pure tone should be read as $10 \mathrm{~dB}$ worse.

To address these difficulties in the TEN test, Moore ${ }^{22}$ presented a new version published on a $\mathrm{CD}$ on the site hearing.psychol.cam.ac.uk - the TEN(HL) - now calibrated in dBNA and with pure tone and noise levels corresponding to dial readings.

Although we saw a significant difference between the MT and the AT at all frequencies, the number of inconclusive results (Figure 1) and the calibration procedure for the TEN test version we used in this study, as well as the results obtained by Summers, ${ }^{19}$ who noted divergences between the TEN test and the PTC for 8 out of 18 ears, led us to question the need for further studies to demonstrate the TEN test sensitivity in detecting dead regions in the cochlea.

As Moore ${ }^{5}$ has suggested, higher TEN thresholds may be due to central problems, rather than dead regions in the cochlea. However, we saw a significant difference between the MT and the AT only for sloping and not for flat hearing losses, which suggests a difference in the detection of pure tones in the presence of noise for individuals with hearing loss at high frequencies and those with flat hearing loss.

\section{CONCLUSION}

A critical analysis of our results in this study allows us to conclude that:

- Dead regions in the cochlea were present in 92\% of cases of sloping sensorineural hearing loss and absent in flat hearing loss.

- The TEN test is effective to suggest the presence of dead regions in the cochlea in individuals with sloping sensorineural hearing loss.

\section{REFERENCES}

1. Moore BCJ. Perceptual consequences of cochlear hearing loss and their implications for the design of hearing aids. Ear Hear 1996;17(12):133-61.

2. Moore BCJ, Glasberg BR. A model of loudness perception applied to cochlear hearing loss. Auditory Neuroscience 1997;3:289311.

3. Moore BCJ, Huss M, Vickers DA, Glasberg BR, Alcântara JI. A test for diagnosis of dead regions in the cochlea. Br J Audiol 2000;34:20524.

4. Gravendeel DW, Plomp R. Perceptive bass deafness. Acta Otolaryngol 1960;51:549-60.

5. Moore BCJ. Dead regions in the cochlea: diagnosis, perceptual consequences, and implications for the fitting of hearing aids. Trends in Amplification 2001;5:1-34.

6. Moore BCJ. Dead regions in the cochlea: implications for the choice of high-frequency amplification. In: Seewald RC, Gravel JS, Ed. A sound foundation through early amplification 2001: Proceedings of the second international conference. Great Britain: St. Edmundsburry Press; 2002. p.153-66.

7. Huss M, Moore BCJ, Baer T, Glasberg B. Perceptions of pure tones by listeners with and without a dead region. Br J Audiol 2001;35:14950.

8. Eguti EY. Identificação das zonas mortas na cóclea utilizando a técnica de mascaramento com ruído branco [dissertação]. São Paulo: Universidade Federal de São Paulo; 2002.

9. Vickers DA, Moore BCJ, Baer T. Effects of low-pass filtering on the intelligibility of speech in quiet for people with and without dead regions at high frequencies. J Acoustic Soc Am 2001;110 (2):116475 .

10. Davis H, Silverman RS. Hearing and deafness. New York: Rinehart \& Winston;1978.

11. Veniar FA. Individual masking levels in pure tone audiometry. Arch Otolaryng 1965;82:518-21.

12. Carhart R, Jerger JF. Preferred method for clinical determination of pure-tone thresholds. J Speech Hear Dis 1959;24:330-45.

13. Moore BCJ. Practical application of the TEN test for diagnosis of dead regions. Iranian Audiology 2002;1:17-21.

14. Moore BCJ. Response to "articulation index predictions for hearing impaired listeners with and without cochlear dead regions". J Acoustic Soc Am 2002, 111:2549-671.

15. Henderson D, Salvi RJ, Boettcher FA, Clock AE. Correlatos Neurofisiológicos da perda auditiva neurossensorial. In: Katz J, Ed. Tratado de audiologia Clínica. São Paulo: Manole; 1999, p.36-55.

16. Bess FH, Humes LE. Fundamentos de Audiologia. Porto Alegre: Artmed; 1998.

17. Lent R. Cem bilhões de neurônios:conceitos fundamentais de neurociência. São Paulo: Atheneu; 2001.

18. Evans EF. The sharping of frequency selectivity in the normal and abnormal cochlea. Audiology 1975;14:419-42.

19. Summers V, Molis MR, Müsch H, Walden BE, Surr RK, Cord MT. 
Identifying dead regions in the cochlea: psychophysical tuning curves and tone detection in threshold-equalizing noise. Ear Hear 2003;24(2):133-142.

20. Halpin C. The tunning curve in clinical audiology. Am J Audiol
2002;11:56-64.

21. Moore BCJ. Dead regions en the cochlea: conceptual foundations, diagnosis, and clinical applications. Ear Hear 2004;25:98-116.

22. Moore BCJ, Glasberg BR, Stone MA. A new version of the TEN test with calibrations in dBHL. Ear Hear 2004;25(5):478-487. 